\title{
IMPROVEMENT OF POWER EFFICIENCY OF MACHINES FOR RESISTANCE SPOT WELDING BY LONGITUDINAL COMPENSATION OF REACTIVE POWER
}

\author{
A.A. PISMENNY \\ E.O. Paton Electric Welding Institute, NASU \\ 11 Bozhenko Str., 03680, Kiev, Ukraine. E-mail: office@paton.kiev.ua
}

\begin{abstract}
Considered is the operation of supply system of a single-phase machine for resistance spot welding (RSW) with introducing of scheme of longitudinal compensation of reactive power into the primary circuit of welding transformer. Machines for RSW are characterized by a high consumed power, the significant part of which is a reactive component. This leads to increase in general installed power of working regions and asymmetry of loading phases of supply distribution three-phase mains. It is shown in the work that system with a longitudinal compensator is well interacted with a standard thyristor controller of power of machine and allows keeping a high value of power factor within the range of phase control up to $60^{\circ}$. The application of longitudinal compensation gives technological advantages of spot welding, as the power factor of machine with a compensator depends little on the resistance of welding contact. Therefore the welding of metals in the wide range of specific resistances is possible: from low-carbon steels up to some light alloys and metals with protective coatings. Low cost of additional equipping of existing machines with longitudinal compensator with a simultaneous improvement of their technological properties makes the method of longitudinal compensation challenging for industrial application. 7 Ref., 1 Table, 4 Figures.
\end{abstract}

$\boldsymbol{K} \boldsymbol{e} \boldsymbol{y} \boldsymbol{w} \boldsymbol{o r d} \boldsymbol{s}:$ resistance spot welding, power system, compensation of reactive power, power factor

Welding equipment for resistance spot welding (RSW), in particular for AC welding at industrial frequency, is characterized by high consumed power. At present the problem of optimizing power consumption of power source of welding equipment is urgent for industry. The existing park of equipment for RSW consists mainly of old machines with a single-phase power supply. This is due to the fact that these machines are long-serviced and purchase of new ones with more updated systems of supply requires significant capital investments.

In works [1, 2] the ways of improving the power efficiency of supply systems are out-of-date RSW machines were analyzed. The method of longitudinal compensation of a reactive component of power in single-phase welding AC machines of industrial frequency is known [3]. The aim of the present paper is to study some peculiarities of this method as-applied to RSW machines.

It is known that any machine for resistance welding at industrial frequency current including for spot one possesses a significant reactive resistance. The reactive power, partially consumed for heating of welding transformer and current- carrying welding circuit, is commeasurable with active one consumed for heating of welding zone. Due to this the full electric power, consumed by such welding machine, is increased and total installed power of the working region is increased.

Longitudinal compensation of reactive component of power applied to RSW machine represents the connection of bank of capacitors $C$ in series with primary winding of welding transformer $T$ (Figure 1). General principle consists in attaining, when possible, perfect compensation of reactive resistance of circuit, that means the equality by absolute value of reactive (inductive) resistance of the secondary circuit and reactive (capacitive) resistance of bank of capacitors, reduced to the secondary side: $X_{L}+X_{C}^{\prime}=0$ (where $X_{L}=\omega L$ is the inductive resistance of the secondary circuit; $\omega$ is the circular frequency; $L$ is the

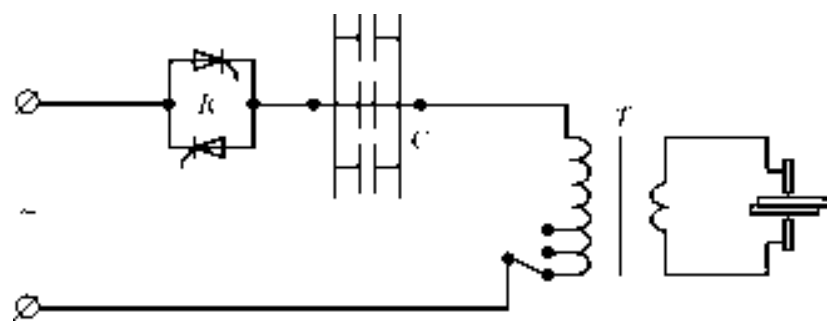

Figure 1. Scheme of supply system of RSW machine with longitudinal compensation of reactive component of power (for designations see the text) 
inductance; $X_{C}^{\prime}$ is the capacitive resistance of bank of capacitors, reduced to secondary winding of a welding transformer). At the absence of compensation the short circuit resistance of machine is $Z_{\mathrm{m}}=\sqrt{X_{L}^{2}+\left(R_{\mathrm{c}}+R_{\mathrm{w} . \mathrm{c}}\right)^{2}}$.

At compensation, in a perfect case the condition is fulfilled, where $Z_{\mathrm{m}}$ reaches the minimum value, i.e. it almost becomes equal to the full active resistance of circuit $R_{, \mathrm{c}}\left(R_{\mathrm{w} . \mathrm{c}}\right.$ is the active resistance of welding contact).

Thus, $Z_{\mathrm{m}}$ value is tending to the sum of values of active resistances and

$$
\cos \varphi=\frac{R_{\mathrm{c}}+R_{\mathrm{w} . \mathrm{c}}}{Z_{\mathrm{m}}} \rightarrow 1 .
$$

At this condition the supply distribution network considers the welding machine as an active load, and full power consumed from mains is drastically decreased. Taken into account that inductive resistance $X_{L}$ in RSW machines greatly exceeds the active $R_{\mathrm{c}}$ [4], the values of consumed full power can be reduced by 2 and more times.

Let us consider an example. Let the welding current of the machine without compensator be

$$
I_{2}=\frac{\sqrt{S^{\prime}}}{\sqrt{R^{2}+X_{L}^{2}}},
$$

where $S^{\prime}$ is the full consumed power reduced to the secondary circuit; $R$ is the full active resistance of the secondary circuit including resistance of the welding contact.

Let us assume that the same values should be provided by machine with the compensator:

$$
I_{2}=\sqrt{\frac{S_{\mathrm{c.d}}^{\prime}}{R}}
$$

where $S_{\text {c.d }}^{\prime}$ is the full consumed power reduced to the secondary circuit of machine with a compensating device.

Consequently, at one and the same secondary current the consumed power of machine with a compensator is

$$
S_{K}^{\prime}=\frac{S^{\prime} R}{\sqrt{R^{2}+X_{L}^{2}}}=\frac{S^{\prime}}{\sqrt{1+\operatorname{tg}^{2}} \frac{-}{\varphi}} .
$$

Reactive resistance (for larger part of RSW machines of a medium power), reduced to the secondary circuit, is not less than $150 \mu \mathrm{Ohm}$ [4], active resistance depending on design version is in the ranges of $50-100 \mu \mathrm{Ohm}$, resistance of welding contact of steels of carbon group is 50$100 \mu \mathrm{Ohm}$. So, in the machine without a compensator

$$
\operatorname{tg} \varphi=\frac{X_{L}}{R}=\frac{150}{(50-100)+(50-100)}=1.50-0.75 .
$$

Here, the ratio of powers is

$$
\frac{S^{\prime}}{S_{K}^{\prime}}=\sqrt{1+\operatorname{tg}^{2}}-\bar{\varphi}=1.80-1.25 .
$$

In welding of aluminium and magnesium alloys this ratio is higher as the resistance of welding contact is decreased to $10-20 \mu \mathrm{Ohm}$ :

$$
\frac{S^{\prime}}{S_{K}^{\prime}}=2.69-1.60 \text {. }
$$

As is seen, the use of a longitudinal compensation even in the first approximation allows obtaining the same active power at loading at the lower secondary voltage of welding transformer. Therefore, in the given case it is possible to increase the transformation factor, that respectively will decrease the secondary voltage, primary current and consumed power.

Application of longitudinal compensation of reactive power decreases load to the transformers of distribution substations, that is very important at repeated - short time mode of RSW machines operation, and also allows applying the currentcarrying conductors with much smaller section for the machines connection.

At evident advantages of method of longitudinal compensation there are problems of an applied nature, requiring special investigations and calculations.

The first task is the setting up of machines with a compensator for the required welding mode. In conventional machines this is realized by switching the transformer stages. In the given case this leads to violation of compensation as the inductance is changed. It is possible to adjust the primary voltage by means of autotransformer connected between the mains and machine with a compensator, but this solution requires additional large expenses. It is more effective to apply the phase control, the peculiarities of which in using in welding machines with longitudinal compensation are given below.

The second task (the work aim) consists in possibility of attaining the full compensation under real conditions and retaining setting up during the whole operating cycle. It is known that the effect of ferromagnetic masses into welding circuit, such as dimensional and massive products being welded, improves reactive resistance of welding contour of the machine [4]. Besides, at the constant setting of mode for welding of one and the same product and from a product to product the active resistance of welding contact is 
changed. If it is commeasurable with active resistance of contour, then the parameters of welding mode can change dramatically.

The phase control at conventional machines for spot welding is performed using thyristor contactor $K$ (see Figure 1). The phase of connection determines the current necessary to produce the welded joint (Figure 2).

To eliminate constant component in current and saturation of transformer, the angle of control by thyristor $\varphi_{1}$ should be within the ranges $\varphi<\varphi_{1}<(\pi-\varphi)$. The higher $\varphi_{1}$, the lower is the current, which is changed by sinusoidal low without interruption only in case if $\varphi_{1}=\varphi$. At other values of this angle the pauses are occurred in steady mode between current pulses, moreover, the total pulse duration and next pause is $\pi$, and current pulse duration of semi-period is $\theta_{1}=\pi+$ $+\varphi_{1}-\varphi$.

If even the thyristor contactor is not used, and the welding mode is defined by selected stage of welding transformer, $\varphi$ is not a constant value in practice. In traducing of dimensional ferromagnetic materials into welding circuit, as well as increase in stickout of electrodes, leads to the growth of welding circuit inductance $L$ and angle $\varphi$. If the welding mode is defined by angle of thyristor control $\varphi_{1}$, then it is necessary to find out the degree of system «recompensation» at such control.

The scheme of replacement of electrical part of RSW machine without a compensator, which is reduced to the secondary circuit and does not consider the current of transformer idle run for simplification of calculations [5], is shown in Figure 3, $a$ and described by differential equation of the first order:

$$
U_{m} \sin \left(\theta+\varphi+\varphi_{1}\right)=i R+X_{L} \frac{d i}{d \theta},
$$

where $\theta=\omega t ; i$ is the instantaneous current.

As basic values we take $U_{m}$ as an amplitude value of the secondary voltage, $X_{L}$ as an inductive resistance of the machine, $\varphi_{1}$ as an angle of thyristor control and $\varphi$ as a phase angle.

Let us go on to the relative units:

$$
\sin \left(\theta+\varphi+\varphi_{1}\right)=i \frac{X_{L}}{U_{m}} \frac{R}{X_{L}}+\frac{X_{L}}{U_{m}} \frac{d i}{d \theta}
$$

or

$$
\sin \left(\theta+\varphi+\varphi_{1}\right)=\frac{i_{e}^{*}}{t L}+\frac{d i_{e}^{*}}{d \theta},
$$

where

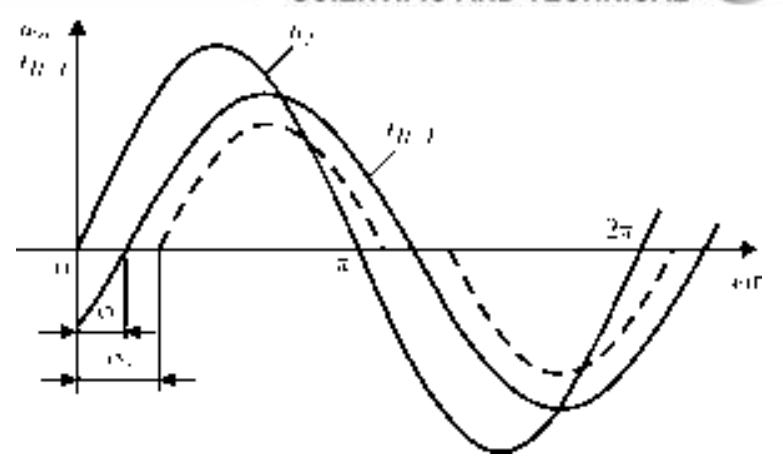

Figure 2. Dependence of instantaneous values of voltage $u_{2}$ and current $i_{R, L}$ on angle $\omega t$ for a period

$$
i_{e}^{*}=i \frac{X_{L}}{U_{m}}, \quad t L=\frac{X_{L}}{R}=\operatorname{tg} \varphi \quad \text { and } \quad R=R_{\mathrm{c}}+R_{\mathrm{w} . \mathrm{c}} .
$$

Using these expressions, let us define the value of welding machine $\chi-$ the power factor important for further calculations. In this case the active power for steady mode is

$$
P=\left(\frac{i_{e}^{*} U_{m}}{X_{L}}\right)^{2} R
$$

full power

$$
S=\frac{i_{e}^{*} U_{m}}{X_{L}} \frac{U_{m}}{\sqrt{2}}
$$

i.e.

$$
\chi=\frac{P}{S}=\frac{i_{e}^{*} U_{m}^{2}}{X_{L}^{2}} \frac{R \sqrt{2} X_{L}}{i_{e}{ }^{2} U_{m}^{2}}=\frac{1.4 i_{e}^{*}}{t L} .
$$

The simplified scheme of replacement of electric part of machine with a compensator is shown in Figure 3, $b$, where $\Gamma$-shaped scheme of transformer replacement is used (without account for circuit of open-circuit current passing). Therefore, it is taken into account that equation (1) is transformed into equation for circuit $R-L-C$ (in relative units):

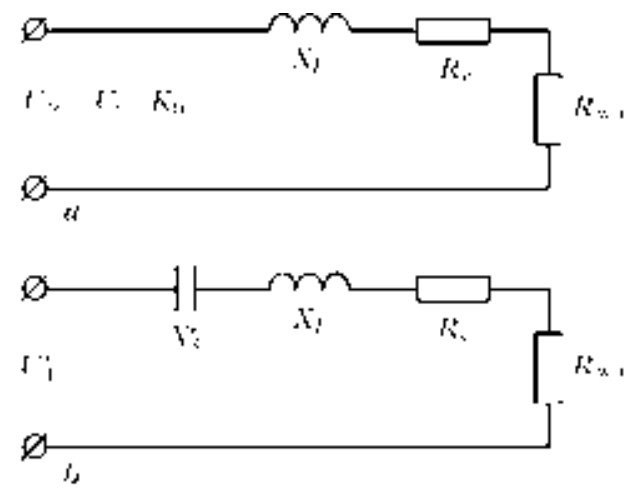

Figure 3. Scheme of replacement of welding machine without $(a)$ and with $(b)$ compensator reduced to the secondary side of transformer (transformation coefficient $K_{\mathrm{tr}}=1$; $U_{i}^{\prime}$ - primary voltage reduced to the secondary circuit) 
SCIENTIFIC AND TECHNICAL

Comparative characteristics of serial RSW machines

\begin{tabular}{||c|c|c|c|c||}
\hline $\begin{array}{c}\text { Type of } \\
\text { machine }\end{array}$ & $R, \mu \mathrm{Ohm}$ & $X_{L}, \mu \mathrm{Ohm}$ & $t L$ & $\chi$ \\
\hline MT-1818 & 93 & 307 & 3.30 & 0.29 \\
\hline MT-1618 & 121 & 359 & 2.97 & 0.31 \\
\hline MT-2102 & 95 & 400 & 4.21 & 0.24 \\
\hline MT-2002 & 102 & 479 & 4.70 & 0.21 \\
\hline MT-4019 & 79 & 220 & 2.78 & 0.34 \\
\hline
\end{tabular}

$$
\sin \left(\theta+\varphi+\varphi_{1}\right)=\frac{i_{e}^{*}}{t L}+\frac{d i_{e}^{*}}{d \theta}+\frac{X_{L}}{X C} \stackrel{*}{U} \dot{C}_{\mathrm{r}},
$$

where $U_{C_{\mathrm{r}}}^{\prime}=U_{C}^{\prime} / U_{m}$ is the relative value of voltage at capacitor: $U_{C}^{\prime}$ is the voltage at capacitor reduced to the secondary side of welding transformer.

Now we shall determine how the effect from longitudinal compensation is changed at change of angle of thyristor control $\varphi_{1}$ using the standard power thyristor contactor. For this purpose we shall take the data of the Table [4] on serial RSW machines into consideration (values of power factors $\chi$ of machines are given at $\varphi_{1}=\varphi$ in the short circuit mode).

For stationary machine with the lowest power factor (MT-2002) at different active resistances $R_{\text {w.c }}$ from 20 (in welding of light alloy parts) up to $180 \mu \mathrm{Ohm}$ (typically in welding of low-carbon steel parts) the data for three versions of connection are calculated: without compensation $\left(X_{C}=\right.$ $=0)$, with partial compensation $\left(X_{C}^{\prime} / X_{L}=\right.$ $=0.75)$ and full compensation $\left(X_{C}^{\prime} / X_{L}=1\right)$, tacking into account (1) and (2).

The comparison diagrams are plotted ( $\mathrm{Fi}^{-}$ gure 4) illustrating dependence $\chi=f\left(R_{\mathrm{c}}\right)$ at different ratios $X_{C}^{\prime} / X_{L}$. Data for their plotting as well as program for calculation are given in [6].

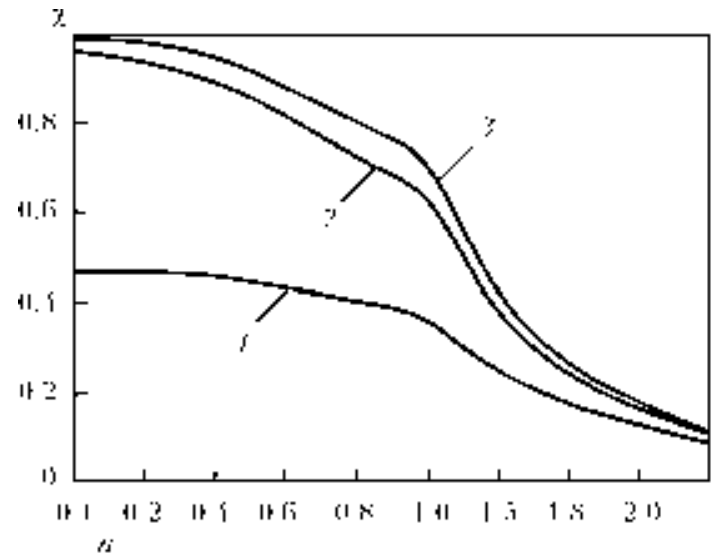

Relative value of voltage at capacitor $U_{C_{\mathrm{r}}}^{\prime}$ (reduced to the secondary side, using modulus), relative value of current $i_{e}$ and power factor $\chi$ were calculated.

Diagrams illustrate the calculated values of power factors depending on active resistance of load (function of angle of thyristor contactor connection) for machines with and without compensator. The significant deviation of $X_{L}$ can be caused by switching the stages of welding transformer, which can be from 4 up to 12 depending on power, and ratio of the highest voltage to the list one does not exceed usually 2.6 [5]. Therefore in many-turn transformers the transition to the next stages will not be very noticeable. It is seen from the diagram that even at a partial compensation the power factor of machines is greatly increased. In particular, in machine MT-2002 at $R_{\mathrm{c}}=20 \mu \mathrm{Ohm}$ and $\varphi_{1}=0.8$ (about $60^{\circ}$ ) the power factor is equal to 0.71 , and in machine not equipped with a compensator it is 0.39 .

The diagrams illustrate negligible effect on power factor of oscillations $R_{\mathrm{w} . \mathrm{l}}$, changed within the wide ranges. It means that possible changes in transition resistance and specific resistance of metal during heating in the contact zone will little affect the stability of welding quality. Consequently, even in conventional single-phase machine, but equipped with a compensator, the industrial frequency of medium power (up to $100 \mathrm{kVA}$ ) the welding of metal is possible within the wide range of specific strengths - from carbon steels to some grade of light alloys, as well as joining of parts with a preliminary deposited protective coating with a high value of protective resistance. The mentioned possibilities are limited only by technical features of the equipment, i.e. by maximum power of welding transformer, version of the secondary welding circuit, maxi-

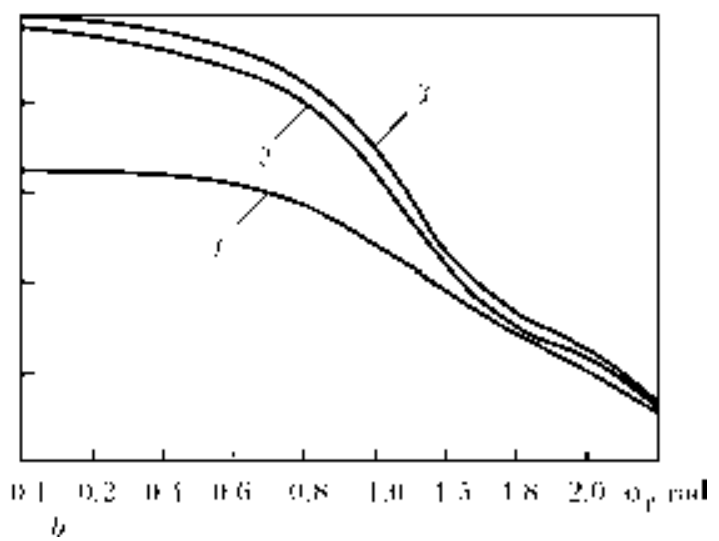

Figure 4. Dependence of power factor $\chi$ of RSW machine with longitudinal compensation on angle $\varphi_{1}$ of connection of thyristor contactor at $R_{\mathrm{w} . \mathrm{c}}=20 \cdot 10^{-6}(a)$ and $180 \cdot 10^{-6}(b): 1-$ without compensation; $2-$ with partial compensation; 3 - with full compensation 
mum force of compression of electrodes and their configuration [7].

Compensation of reactive power allows perform welding with a great saving of electric power. Taking into account that additional equipment of serial welding machine with a compensating device depending on its capacity, adds not more than $15 \%$ to the cost, the term of the compensator payback will be relatively small and shorter depending on the term of machine operation.

The advantages of longitudinal compensation of reactive resistance in RSW machines operating at industrial frequency are evident, and during the development of the new equipment the attention should be paid to these systems.

The continuation of works in this field can be preparation of methodology of systematized calculation of definite parameters of compensators of reactive power by real data obtained in service of updated RSW machine of up to $100 \mathrm{kVA}$ capacity, taking into account the possibility of additional equipment by thyristor contactor of those models, where its application of its technology is rational.

\section{Conclusions}

1. The application of longitudinal compensation of reactive power of RSW machines allows keeping a high value of power factor in the range of phase control of up to $60^{\circ}$ (corresponds to 5-6 stages of multi-turn welding transformer) at implicit dependence on load resistance, that corresponds to practical conditions of the welding machine service.

2. It was found that within the mentioned range of control of angle changes, there is a region of effective application of longitudinal compensation. At further increase of making angle the values of power factors for machines, equipped with compensating devices, are commeasurable with values of machines modes without application of compensation.

3. It was established that in the considered range of phase control the value of power factor of machine with a compensator scarcely depends on load resistance, that allows welding of parts in the wide range of specific resistances.

4. The practical application of systems with longitudinal compensation of reactive power is recommended in single-phase RSW machines of installed power of up to $100 \mathrm{kVA}$ taking into account partial compensation within 10-25\% ranges.

1. Lebedev, V.K., Pismenny, A.A. (2001) Power systems of resistance welding machines. The Paton Welding J., 11, 28-32.

2. Lebedev, V.K., Pismenny, A.A. (2003) Power system of flash-butt welding machines with a transistor inverter. Ibid., 2, 10-12.

3. Zorin, V.V. (1960) Compensation of reactive power of resistance machines by series capacitors. Avtomatich. Svarka, 6, 28-36.

4. Glebov, L.V., Filippov, Yu.I., Chuloshnikov, P.L. (1987) Structure and operation of resistance machines. Leningrad: Energoatomizdat.

5. Paton, B.E., Lebedev, V.K. (1969) Electric equipment for resistance welding. Moscow: Mashinostroenie, 59, 302, 342.

6. Pismenny, A.A. (2008) Increase in efficiency of supply systems of resistance spot welding machines: Syn. of Thesis for Cand. of Techn. Sci. Degree. Kiev.

7. Koubek, P. (2006) Energeticke aspekty pouzivania zvaracich strojov s trojfazovym napajanim. ZvaranieSvarovani, 10, 288-292.

Received 27.03.2013 